\title{
Extinction of a saccharin-lithium association: Assessment by consumption and taste reactivity
}

\author{
RAÚL CANTORA and MATÍAS LÓPEZ \\ Universidad de Oviedo, Oviedo, Spain \\ LUIS AGUADO \\ Universidad Complutense de Madrid, Madrid, Spain \\ and \\ SHADNA RANA and LINDA A. PARKER \\ Wilfrid Laurier University, Waterloo, Ontario, Canada
}

\begin{abstract}
Extinction of a conditioned palatability shift preceded extinction of conditioned taste avoidance whether rats were tested using a within-subjects design or a between-subjects design. In each of two experiments, consumption of $0.1 \%$ saccharin was paired with either $20 \mathrm{ml} / \mathrm{kg}$ of $0.15 \mathrm{M} \mathrm{LiCl}$ or equivolume physiological saline on a single trial. In Experiment 1, on each of 10 extinction trials, rats were given a taste reactivity test immediately prior to a consumption test. In Experiment 2, half of the rats were extinguished by taste reactivity testing and half of the rats were extinguished by a consumption test on each of 10 extinction trials. In both experiments, the aversive reactions of gaping and passive dripping were extinguished in a single trial and the suppression of ingestive reactions was extinguished in 2 trials; however, extinction of taste avoidance required 4-5 trials. These results suggest that rats continue to avoid a lithium-paired flavor even when they do not have an aversion to the taste.
\end{abstract}

When rats experience lithium-induced illness after drinking a novel flavored solution, they subsequently avoid consuming that solution. Suppressed consumption of the lithium-paired taste is reflected not only in reduced intake at the spout (consummatory responding), but also in a reduced tendency to approach the spout (appetitive responding). The relative contributions of suppressed appetitive and consummatory responding are necessarily confounded in the typical consumption test.

The contribution of changes in consummatory responding independently of appetitive responding to taste aversion learning can be evaluated with the taste reactivity (TR) test developed by Grill and Norgren (1978). The TR test measures orofacial and somatic reactions elicited by a brief forced intraoral exposure to a lithium-paired taste. If rats are intraorally infused with a lithium-paired flavor, they display aversive reactions, such as gaping, that are also elicited by exposure to a bitter quinine taste. Furthermore, a lithium-paired flavor elicits suppressed ingestive reactions, such as tongue protrusions. These patterns of responding suggest that the palatability of the illness-

The authors thank Cheryl Limebeer for her expert assistance with these experiments. This research was supported by funding from the Natural Sciences and Research Council of Canada to L.A.P. and from the Ministry of Science and Technology of Spain (MCYT BSO-200303661) to M.L. and to R.C. (FPU, AP2002-2553). Correspondence should be addressed to L. A. Parker, Department of Psychology, University of Guelph, Guelph, ON, N1G 2W1 Canada (e-mail: parkerl@ uoguelph.ca). paired saccharin solution changes in the direction of an aversion, as was initially suggested by Garcia, Hankins, and Rusiniak (1974).

When the conditionally aversive taste is repeatedly presented in the absence of subsequent illness, rats will eventually readily consume that taste (e.g., Berman \& Dudai, 2001; Nolan et al., 1997). However, there is substantial evidence that much of the original learning survives extinction (see Bouton, 2004; Delamater, 2004). For example, Rosas and Bouton (1996) reported that the intake of an extinguished lithium-paired taste does not reach the level of that of the same taste not paired with lithium. This suggests that the hedonic assessment of that taste should not return to preconditioning palatability levels. Although the extinction of taste avoidance learning has been evaluated extensively, the extinction of the conditioned palatability shift has not been investigated using the taste reactivity paradigm.

The following experiments compared the patterns of extinction of both lithium-induced taste avoidance (consumption test) and taste reactivity using a within-subjects design (Experiment 1) and a between-subjects design (Experiment 2).

\section{EXPERIMENT 1}

In Experiment 1, rats received a single conditioning trial during which saccharin consumption was paired with lithium (Group Paired) or saline (Group Unpaired). To equate exposure to lithium, rats in Group Unpaired were injected with lithium and rats in Group Paired were in- 
jected with saline $24 \mathrm{~h}$ after the conditioning trial. During extinction, rats were given a 1-min intraoral infusion of saccharin solution in the taste reactivity chamber followed immediately by $30 \mathrm{~min}$ of access to saccharin solution in a bottle in their home cages. Therefore, the development of extinction of rejection and avoidance of the taste could be tracked within the same animal.

\section{Method}

\section{Subjects}

The subjects were 24 male Sprague-Dawley rats (Charles River Laboratories, St. Constant, Quebec), which weighed 250-350 g on the conditioning day. They were individually housed in stainless steel hanging cages in a colony room kept at $21^{\circ} \mathrm{C}$ on a 12:12-h light: dark schedule with the lights on at $0700 \mathrm{~h}$. Throughout the experiment, the rats were maintained on ad-lib Rat Chow, but they were maintained on a water deprivation schedule described in the procedure section. The procedures were approved by the Wilfrid Laurier University Animal Care Committee according to the guidelines of the Canadian Council on Animal Care.

\section{Surgery \\ One week following their arrival in the laboratory, the rats were implanted with intraoral cannulae. Twenty-four hours prior to the surgical procedure, they were administered a prophylactic antibiotic (Derapin, $100 \mathrm{mg} / \mathrm{kg}$, s.c.; Ayerst). On the day of surgery, the rats were anesthetized with isofluorane gas and administered Anafen (7 mg/kg, s.c.; Merial), a nonsteroidal anti-inflammatory drug with analgesic properties. A 3-cm square of fur was shaved at the back of the neck just above the scapula, and Betadine (Purdue Frederick) and alcohol were rubbed on the skin. A thin-walled 15-gauge stainless steel needle was inserted at the back of the neck, directed subcutane- ously around the ear and brought out behind the first molar inside the mouth. A length of Intramedic polyethylene tubing with an inner diameter of $0.86 \mathrm{~mm}$ and an outer diameter of $1.27 \mathrm{~mm}$ was then run through the needle, after which the needle was removed. Two circular elastic disks were placed over the tubing and drawn to the exposed skin at the back of the neck for the purpose of stabilizing the cannula. The tubing was held secure in the oral cavity by an O-ring, which was sealed behind the tubing prior to cannulation surgery. For the purposes of conditioning and testing, the cannula was connected to the infusion pump (Harvard Apparatus, South Natick, MA) for delivery of the solution by slipping the tubing of the cannula inside a second polyethylene tubing (inner diameter, $1.19 \mathrm{~mm}$; outer diam- eter, $1.70 \mathrm{~mm}$ ) attached to the infusion pump.}

\section{Procedure}

Five days after the surgery, the rats were placed on a water deprivation schedule during which they received $30 \mathrm{~min}$ of water beginning at 0900 in the morning and an additional $30 \mathrm{~min}$ of water beginning at 1700 in the afternoon, for 4 days. The delivery of $30 \mathrm{~min}$ of water at $1700 \mathrm{~h}$ continued throughout the experiment.

The conditioning trial occurred on Day 5. During this trial, the rats received $30 \mathrm{~min}$ of access to a graduated tube containing $0.1 \%$ saccharin solution in the home cage beginning at 0900 . Upon removal of the saccharin, the rats were injected i.p. with either $20 \mathrm{ml} / \mathrm{kg}$ of $.15 \mathrm{M} \mathrm{LiCl}$ (Group Paired; $n=12$ ) or $20 \mathrm{ml} / \mathrm{kg}$ of physiological saline (Group Unpaired; $n=12$ ). On Day 6, all rats received $30 \mathrm{~min}$ of access to water at $0900 \mathrm{~h}$. Two hours later, the rats given $\mathrm{LiCl}$ during conditioning were injected with saline and the rats given saline during conditioning were injected with $\mathrm{LiCl}$, both at the same volume as given on Day 5 . These noncontingent injections ensured that both groups were equally experienced with $\mathrm{LiCl}$. On Days 7 and 8, the rats received water in their home cages for $30 \mathrm{~min}$ at $0900 \mathrm{~h}$.
On Day 9 , the rats were individually placed in a taste reactivity $(\mathrm{TR})$ chamber $(22.5 \times 26 \times 20 \mathrm{~cm})$ made of Plexiglas and their cannula was attached to the infusion pump for fluid delivery. The rats were habituated to the TR procedure by infusion with water for a period of $1 \mathrm{~min}$ at the rate of $1 \mathrm{ml} / \mathrm{min}$. They were then returned to their home cages and allowed to consume water for $30 \mathrm{~min}$. The extinction trials began on Day 10 and continued for each of 10 consecutive days. They were intraorally infused with $0.1 \%$ saccharin for $1 \mathrm{~min}$ at a rate of $1 \mathrm{ml} / \mathrm{min}$ while their orofacial and somatic responses were videotaped from a mirror at a $45^{\circ}$ angle below the TR chamber. Immediately following the infusion, the rats were returned to their home cages and given access to saccharin solution in a graduated tube for $30 \mathrm{~min}$.

On Day 21, the rats were given a two-bottle test; they received access to a tube containing saccharin and a tube containing water for $30 \mathrm{~min}$ in their home cages. The preference for the saccharin was determined by transforming the intake scores into a saccharin preference ratio: (milliliters saccharin consumed)/(milliliters saccharin consumed + milliliters water consumed).

\section{Behavioral Measures}

The videotapes were scored by an observer blind to experimental groups using the Observer (Noldus Information Technology, Sterling, VA) event recording program. The behaviors scored included the frequency of the aversive reaction of gaping, the neutral/mildly aversive reaction of passive dripping, and the ingestive reactions of tongue protrusions, mouth movements, and paw licking. Gaping was defined as rapid, large-amplitude opening of the mandible with retraction of the corners of the mouth. Passive dripping was defined as passively letting the fluid drip from the mouth. Ingestive reactions were defined as the frequency of 2-sec bouts of tongue protrusions (extensions of the tongue out of the mouth), mouth movements (movement of the lower mandible without opening the mouth), and paw licking. The scores for tongue protrusions, mouth movements, and paw licking were summed to provide a total ingestive reaction score.

\section{Results}

\section{Conditioning Trial}

The mean amount of saccharin solution consumed during the conditioning trial did not significantly differ between Groups Paired $(M=17.0, S E M= \pm 1.0)$ and Unpaired $(M=16.3, S E M= \pm 1.0)$ as assessed by an independent $t$ test.

\section{Extinction Trials}

Consumption tests. Figure 1 (top section) presents the mean $( \pm S E M)$ amount of saccharin solution consumed by the Groups Paired and Unpaired on each of the 10 extinction trials. A $2 \times 10$ repeated measures ANOVA revealed a significant group $\times$ trials interaction $[F(9,198)=14.62$, $p<.001]$. As assessed by subsequent independent $t$ tests, on Extinction Trials 1-4, Group Paired drank significantly less saccharin solution than did Group Unpaired $(p \mathrm{~s}<$ $.05)$. In the two-bottle test on Day 21 following the extinction training, Groups Paired $(M=0.6, S E M= \pm 0.1)$ and Unpaired $(M=0.7, S E M= \pm 0.1)$ did not significantly differ $[t(22)=1.21]$ in their preference for saccharin.

Taste reactivity tests. Aversive reactions elicited by a lithium-paired saccharin solution extinguished in a single trial. Group Paired displayed significantly more gaping $[t(22)=2.96, p<.01]$ and passive dripping $[t(22)=$ $2.17, p<.05]$ than did Group Unpaired only on Extinc- 

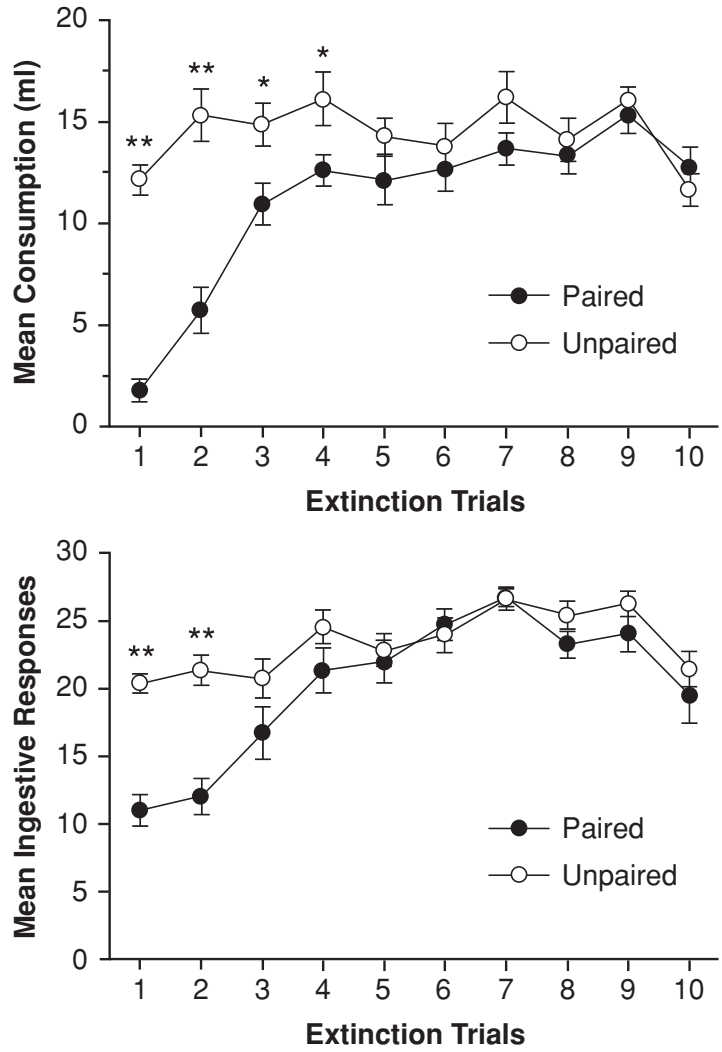

Figure 1. Mean $( \pm S E M) \mathrm{ml}$ saccharin solution consumed during the 30-min consumption test (top panel) and ingestive reactions (frequency of 2-sec bins of tongue protrusions + mouth movements + paw licks; bottom panel) on each extinction trial of Experiment 1. Group difference on each extinction trial: ${ }^{*} p<$ .05 . ${ }^{* *} p<.01$.

tion Trial 1 (see Table 1). The suppression of ingestive reactions displayed by Group Paired extinguished following two extinction trials. The mean $( \pm S E M)$ number of 2 -sec bouts of ingestion reactions (tongue protrusions + mouth movements + paw licking) is presented in Figure 1 (bottom panel). A $2 \times 10$ repeated measures ANOVA revealed a significant group $\times$ trials interaction $[F(9,198)=5.46$, $p<.01]$; as assessed by subsequent $t$ tests, only on Extinction Trials 1 and 2 did Group Paired display fewer ingestive reactions than Group Unpaired $(p \mathrm{~s}<.05)$.

\section{Discussion}

Extinction of the lithium-induced conditioned palatability shift preceded extinction of lithium-induced taste avoidance. Rats displayed extinction of conditioned taste avoidance following four extinction trials; but extinction of conditioned gaping and passive dripping occurred in a single trial, and extinction of suppressed ingestive reactions occurred following two trials.

\section{EXPERIMENT 2}

Considerable evidence suggests that the context is important for extinction (see Bouton, 2004). In Experi- ment 1 , the solutions were conditioned in the rats' home cages and the consumption test occurred in the same context. However, the taste reactivity test was conducted in an environment different from that in which the solutions were initially conditioned. In Experiment 2, both the conditioning sessions and the tests assessing consumption and taste reactivity were conducted in the same context. Furthermore, to directly compare the development of extinction by consumption and by taste reactivity testing, a between-groups design was used; conditioned responding was extinguished in half of the rats by consumption testing (bottle groups), whereas in the other half, it was extinguished by taste reactivity testing (IO groups).

\section{Method}

The subjects were 32 male Sprague-Dawley rats weighing from 250 to $350 \mathrm{~g}$ on the conditioning day. All experimental procedures were the same as in Experiment 1, except as indicated. Half of the rats were implanted with intraoral cannulae as described in Experiment 1; 2 rats lost their cannulae, however, resulting in 14 rats in the IO groups.

All trials occurred in the taste reactivity context unless otherwise stated. On each of 4 days, rats were trained to drink water from a graduated tube (bottle) for $5 \mathrm{~min}$ in the morning (beginning at $0900 \mathrm{~h}$ ) in the taste reactivity chamber. At $1700 \mathrm{~h}$ on each day of the experiment, they were given an additional 60 min of water in their home cages.

On Day 5 , starting at $0900 \mathrm{~h}$, the rats received $0.1 \%$ saccharin solution by bottle for $5 \mathrm{~min}$ in the TR chamber followed by an injection of $20 \mathrm{ml} / \mathrm{kg}$ of $.15 \mathrm{M} \mathrm{LiCl}$ (Group Paired, $n=16$ ) or equivolume saline (Group Unpaired, $n=14$ ). On Day 6, all rats received 5 min of access to water by bottle in the TR chamber, beginning at $0900 \mathrm{~h}$. At $1300 \mathrm{~h}$, the rats in Group Unpaired were injected with $20 \mathrm{ml} / \mathrm{kg}$ of .15 M LiCl and the rats in Group Paired were injected with equivolume of saline.

On Day 7, at $0900 \mathrm{~h}$, the rats in the TR groups (Paired IO, $n=8$; Unpaired IO, $n=6$ ) were intraorally infused with water for $5 \mathrm{~min}$ at the rate of $1 \mathrm{ml} / \mathrm{min}$ and the rats in the bottle groups (Paired Bottle, $n=8$; Unpaired Bottle, $n=8$ ) received access to water in the graduated tube for $5 \mathrm{~min}$ in the TR chamber at $0900 \mathrm{~h}$.

Extinction training occurred on Days 8-17. Rats in the bottle groups were presented with $0.1 \%$ saccharin solution in a graduated tube in the TR chamber for $5 \mathrm{~min}$, beginning at $0900 \mathrm{~h}$, and the amount consumed was measured. Their behavior was videotaped during the consumption tests. In order to equate exposure to the CS flavor, the overall mean amount consumed by the bottle-tested Group Paired on each extinction trial determined the amount of saccharin solution that would be intraorally infused $(1 \mathrm{ml} / \mathrm{min})$ in the IO groups on that trial. The IO groups were exposed to saccharin for 1 min on Extinction Trials 1-3, for 2 min on Trial 4, for 3 min on Trials 5 and 6 , and for 5 min on Trials 7-10. Only the first minute of exposure was videotaped.

On Day 18 , the rats were all given a two-bottle test during which they were presented with two graduated tubes, one containing $0.1 \%$ saccharin solution and the other containing water; this was done in

Table 1

Mean ( \pm Standard Error) Frequency of Gaping and Passive Dripping Displayed by Groups Paired and Unpaired on Extinction Trial 1 of Experiment 1

\begin{tabular}{cccccc}
\hline & \multicolumn{2}{c}{ Gape } & & \multicolumn{2}{c}{ Passive Drip } \\
\cline { 2 - 3 } \cline { 5 - 6 } Group & $M$ & $S E M$ & & $M$ & $S E M$ \\
\hline Paired & 1.75 & \pm 0.59 & & 3.83 & \pm 1.41 \\
Unpaired & 0 & & & 0.67 & \pm 0.33 \\
\hline
\end{tabular}


the TR chamber for $5 \mathrm{~min}$, beginning at $0900 \mathrm{~h}$. The amounts consumed were transformed into a saccharin preference ratio: (milliliters saccharin consumed $) /($ milliliters saccharin consumed + milliliters water consumed). On Day 19, the rats were all given a second twobottle test in their home cages.

\section{Results}

\section{Conditioning Trial}

On the conditioning trial, the groups did not differ in the amount of saccharin solution consumed during the 5-min consumption test that preceded $\mathrm{LiCl}$ or saline administration as assessed by a $2 \times 2$ between-groups ANOVA (Group Paired IO, $M=4.8, S E M= \pm 1.5$; Group Paired Bottle, $M=5.0, S E M= \pm 0.5$; Group Unpaired IO, $M=$ 5.7, $S E M= \pm 0.8$; Group Unpaired Bottle, $M=5.3$, $S E M= \pm 0.7)$.

\section{Extinction Trials}

Bottle groups. Figure 2 (top panel) presents the mean $( \pm S E M)$ milliliters of saccharin solution consumed by the rats that were extinguished by bottle. A $2 \times 10$ mixed factors ANOVA revealed a significant group $\times$ trials interaction $[F(9,126)=7.79, p<.001]$. As assessed by subsequent $t$ tests, on Extinction Trials 1-5, Group Paired drank significantly less saccharin during the 5-min bottle test than did Group Unpaired ( $p \mathrm{~s}<.05$ ). Furthermore, analysis of the videotapes revealed that when tested by bottle, only on Extinction Trial 1 (see Table 2) did Group Paired display significantly more gaping than Group Unpaired $[t(14)=2.62, p<.025]$.

IO groups. Among the IO tested rats, the aversive reactions of gaping and passive dripping extinguished in a single trial. A $2 \times 10$ repeated measures ANOVA revealed significant group $\times$ trials interactions for the behaviors of gaping $[F(9,108)=2.86, p<.01]$ and passive dripping $[F(9,108)=2.29, p<.025]$. Only on Extinction Trial 1 did Group Paired display significantly more gaping $[t(12)=2.12, p<.05]$ and passive dripping $[t(12)=$ $2.31, p<.05]$ than Group Unpaired (see Table 2).

As in Experiment 1, extinction of suppressed ingestive reactions preceded extinction of suppressed consumption. Figure 2 (bottom panel) presents the mean number of 2 -sec bins of ingestive reactions (tongue protrusions + mouth movements + paw licking) among the IO Groups. A $2 \times$ 10 mixed factors ANOVA revealed a significant group $\times$ trials interaction $[F(9,108)=2.02, p<.05]$. Only on Extinction Trials 1 and 2 did Group Paired display significantly fewer ingestive reactions than Group Unpaired $(p s<.01)$, as assessed by independent $t$ tests.

\section{Two-Bottle Tests}

Figure 3 presents the mean $( \pm S E M)$ saccharin preference ratio displayed by the various groups during the twobottle test given the day after the final extinction trial in the TR chamber and on the next day in the home cages. Among the bottle-extinguished groups, regardless of whether the rats were tested in the conditioning/extinction context (TR chamber) or in a different context (home cage) Groups Paired and Unpaired did not significantly differ in saccha-
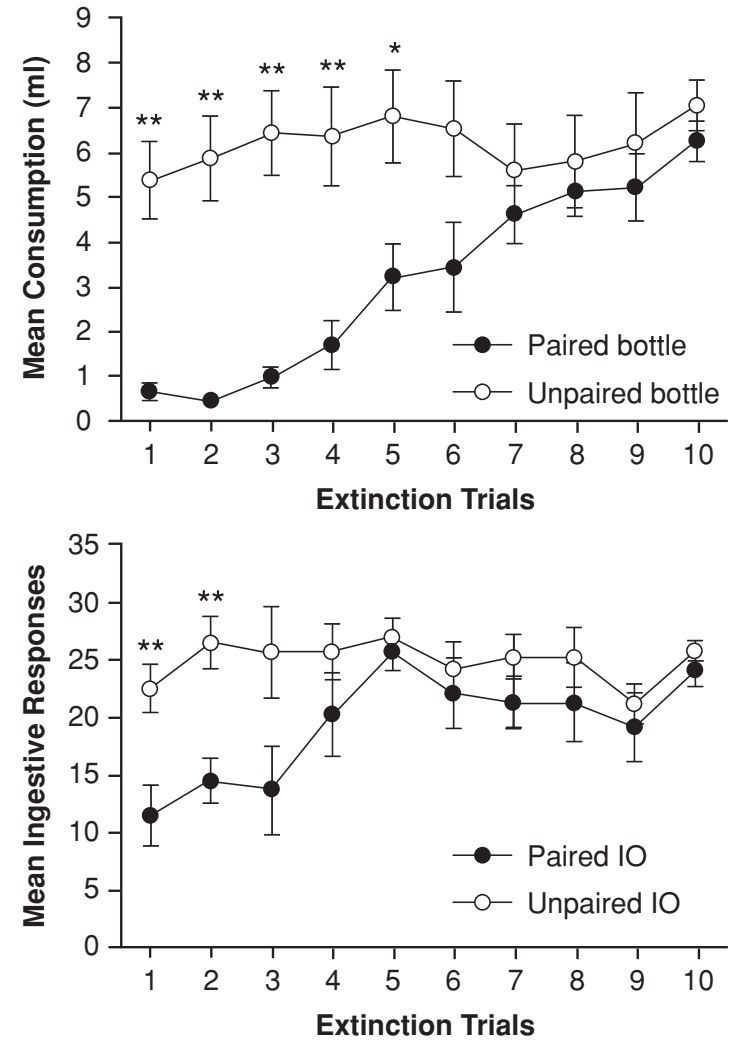

Figure 2. Mean ( $\pm S E M) \mathrm{ml}$ saccharin solution consumed during the 5-min consumption test by bottle-tested groups (top panel) and the ingestive reactions (frequency of 2-sec bins of tongue protrusions + mouth movements + paw licks; bottom panel) during the 1-min TR test by IO groups in Experiment 2. Group difference on each extinction trial: ${ }^{*} p<.05 .{ }^{* *} p<.01$.

rin preference scores $[t \mathrm{~s}(14)<0.5]$. However, among the IO extinguished groups, Group Paired showed lower saccharin preference scores than did Group Unpaired when they were tested in the conditioning/extinction context $[t(12)=2.26, p<.05]$, and when they were tested on the next day in their home cages $[t(12)=2.41, p<.05]$.

\section{Discussion}

Extinction of the flavor-drug association differed whether it was consumed from a drinking spout or administered through an intraoral cannula. Rats continued to avoid consumption of a lithium-paired saccharin solution during extinction training even when they no longer displayed the conditioned palatability shift. In fact, Group Paired showed more aversive reactions of gaping than did Group Unpaired only on the first extinction trial, whether the rats were tested by bottle or by intraoral infusion. The suppressed ingestive reactions persisted only for the first two extinction trials, whereas suppressed consumption persisted for five trials when they were only tested in a 5-min session.

The results of the two-bottle tests revealed that regardless of whether the rats were tested in the conditioning/ extinction TR context or in their home cages, the rats extinguished by actively consuming saccharin from a bottle 
Table 2

Mean ( \pm Standard Error) Frequency of Gapes (IO and Bottle Groups) and Passive Drips (IO Groups) Displayed on Extinction Trial 1 of Experiment 2

\begin{tabular}{lcclll}
\hline \multirow{2}{*}{\multicolumn{1}{c}{ Group }} & \multicolumn{2}{c}{ Gape } & & \multicolumn{2}{c}{ Passive Drip } \\
\cline { 2 - 3 } \cline { 5 - 6 } & $M$ & SEM nnny & & $M$ & SEM \\
\hline Paired IO & 3.25 & \pm 1.20 & & 5.38 & \pm 1.93 \\
Unpaired IO & 0 & & & 0.167 & \pm 0.16 \\
Paired bottle & 3.87 & \pm 1.48 & & \\
Unpaired bottle & 0 & & & & \\
\hline
\end{tabular}

no longer displayed an avoidance of the saccharin following 10 extinction trials. On the other hand, the rats extinguished by IO exposure did not display complete extinction of their avoidance of saccharin when tested in the conditioning/extinction TR context or when tested on the following day in their home cages. Although the conditioned palatability shift had extinguished early during extinction training in Group Paired IO, the avoidance of the lithium-paired taste had not extinguished even after $10 \mathrm{IO}$ exposures.

\section{GENERAL DISCUSSION}

The present experiments are the first of which we are aware to systematically compare the extinction of taste avoidance and taste reactivity reactions. The pattern of results was similar in Experiment 1 using a within-subjects design and in Experiment 2 using a between-subjects design. In addition, in Experiment 1 the TR test occurred in a context different from the conditioning context, but in Experiment 2, the conditioning and extinction contexts were the same. Regardless of these differences, in both experiments, conditioned gaping and passive dripping extinguished in a single trial and conditioned suppression of ingestive reactions extinguished in two trials, despite the several trials that were necessary to extinguish conditioned taste avoidance.
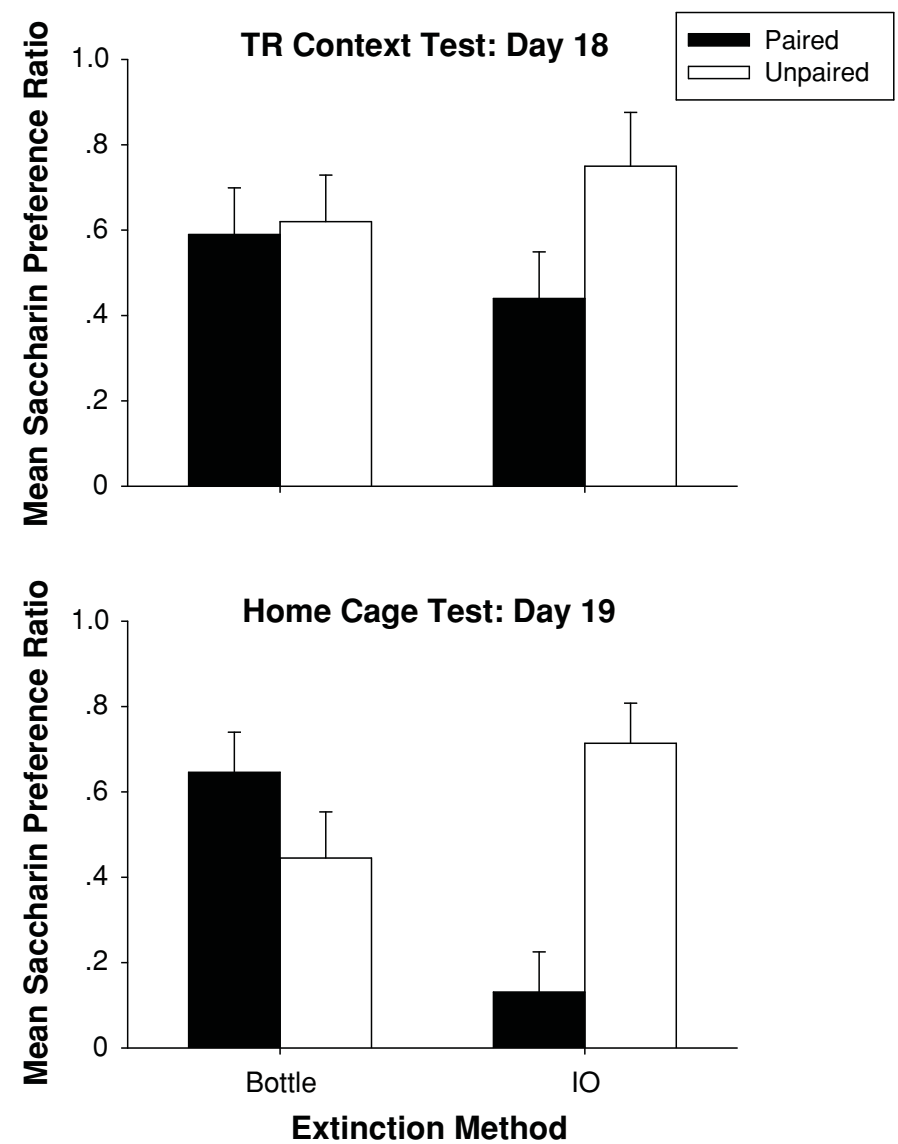

Figure 3. Mean $( \pm S E M)$ preference ratio $[(\mathrm{ml}$ saccharin consumed $) /$ ( $\mathrm{ml}$ saccharin $+\mathrm{ml}$ water consumed)] during the 2-bottle tests that followed 10 extinction trials by Groups Paired and Unpaired extinguished by bottle and by $I O$ infusion. The top panel presents the preference ratios displayed on Day 18 when the rats were tested in the conditioning/extinction context, and the bottom panel presents the preference ratios displayed on Day 19 when the rats were tested in their home cages. 
Our results indicate that taste avoidance is maintained even after taste aversion is extinguished. We (Parker, 2003) have suggested that taste avoidance is different from taste aversion, because rats learn to avoid a taste paired with a rewarding drug, such as amphetamine, but they do not develop an aversion to that taste as measured by rejection reactions in the taste reactivity test. Of course, one might argue that the failure to detect rejection reactions in the TR test with corresponding taste avoidance simply reflects differential sensitivity of the measures. That is, if rewarding drugs simply produce a weaker taste-drug association than do emetic drugs, then this association might be detected in a sensitive intake test, but might not be detected in a less sensitive TR test. Zalaquett and Parker (1989) specifically addressed this issue; when doses were adjusted to produce weaker taste avoidance with lithium $(12 \mathrm{mg} / \mathrm{kg})$ than with amphetamine $(3 \mathrm{mg} / \mathrm{kg})$, only the lithium-paired flavor elicited rejection reactions in the TR test.

The much more rapid extinction of lithium-induced taste rejection than of taste avoidance in the present experiments suggests that avoidance is maintained in the absence of an aversion. On the other hand, it is also possible that the consummatory test is a more sensitive measure of a saccharin-lithium association than the TR test is, and that extinction of the former therefore proceeds more slowly. The avoidance test requires extinction of both the preparatory responses of approach to the bottle and the consummatory responses of drinking from the spout, whereas the TR test requires only extinction of the consummatory reactions during a forced infusion of the drug. It is conceivable that the suppressed preparatory responses are more resistant to extinction than the consummatory responses are. Indeed, it has been reported that taste avoidance measured by bottle consumption extinguishes more slowly than taste avoidance measured by intraoral consumption (Fouquet, Oberling, \& Sandner, 2001; Wolgin \& Wade, 1990; Yamamoto, Fresquet, \& Sandner, 2002).

Furthermore, since the rats were conditioned by active consumption of the saccharin by bottle, both the preparatory and the consummatory responses may have become associated with illness. It may be the case that the appetitive behaviors, in addition to the consummatory behaviors, became associated with the toxic effects of lithium (e.g., Cross-Mellor, Roberts, Kavaliers, \& Ossenkopp, 2003). Therefore, the bottle-tested group may have shown greater resistance to extinction not only because the consummatory responses must be extinguished, but also because the preparatory responses must be extinguished. The lack of extinction of the preparatory responses in the IO extinguished group may have been responsible for maintaining avoidance in the two-bottle test among the IO conditioned group after the extinction procedure was completed.

It might also be the case that avoidance and reactivity measures reflect two distinct aspects of the conditioned response. Konorski (1967) proposed that an unconditioned stimulus (US) is represented by multiple nodes in the memory system, including the representation of the emotional characteristics of the US and the sensory characteristics of the US. Wagner and Brandon (1989) suggested that the activity of emotional nodes is more persistent than the activity of the sensory nodes. Preparatory responses (appetitive responses toward the bottle) are formed by the association of the conditioned stimulus (CS) with the emotional characteristics, and more specific consummatory responses are formed by the association of the CS with the sensory characteristics of the US (Wagner \& Brandon, 1989). According to such an analysis, the avoidance test may primarily measure a conditioned emotional response (i.e., fear), but the TR test may primarily measure a sensory-specific response (i.e., sickness) that is less resistant to extinction (Parker, 2003; Wagner \& Brandon, 1989). Such an explanation is supported by findings that the establishment of lithium-induced conditioned rejection of saccharin solution is prevented by pretreatment with antiemetic agents (Limebeer \& Parker, 1999, 2000, 2003), but such agents do not even attenuate lithium-induced conditioned saccharin avoidance. Regardless of the mechanism, it is clear that rejection reactions as assessed by the TR test extinguish much more rapidly than does taste avoidance as assessed by consumption from a bottle.

\section{REFERENCES}

Berman, D. E., \& Dudai, Y. (2001). Memory extinction, learning anew, and learning the new: Dissociations in the molecular machinery of learning in cortex. Science, 291, 2417-2419.

Bouton, M. E. (2004). Context and behavioral processes in extinction. Learning \& Memory, 11, 485-494.

Cross-Mellor, S. K., Roberts, S., Kavaliers, M., \& Ossenkopp, K.-P. (2003). Activation of the immune system in rats with lipopolysaccharide reduces voluntary sucrose intake but not intraoral intake. Pharmacology Biochemistry \& Behavior, 76, 153-159.

Delamater, A. R. (2004). Experimental extinction in Pavlovian conditioning: Behavioural and neuroscience perspectives. Quarterly Journal of Experimental Psychology, 57B, 97-132.

Fouquet, N., Oberling, P., \& Sandner, G. (2001). Differential effect of free intake versus oral perfusion of sucrose in conditioned taste aversion in rats. Physiology \& Behavior, 74, 465-474.

Garcia, J., Hankins, W. G., \& RusiniaK, K. W. (1974). Behavioral regulation of the milieu interne in man and rat. Science, 185, 824-831.

Grill, H. J., \& Norgren, R. (1978). The taste reactivity test: I. Mimetic responses to gustatory stimuli in neurologically normal rats. Brain Research, 143, 263-279.

KONORSKI, J. (1967). Integrative activity of the brain: An interdisciplinary approach. Chicago: University of Chicago Press.

LimebeER, C. L., \& PARKer, L. A. (1999). Delta-9-tetrahydrocannabinol interferes with the establishment and the expression of conditioned rejection reactions produced by cyclophosphamide: A rat model of nausea. NeuroReport, 10, 3769-3772.

Limebeer, C. L., \& PARKer, L. A. (2000). The antiemetic drug ondansetron interferes with lithium-induced conditioned rejection reactions, but not lithium-induced taste avoidance in rats. Journal of Experimental Psychology: Animal Behavior Processes, 26, 371-384.

Limebeer, C. L., \& Parker, L. A. (2003). The 5-HT ${ }_{1 \mathrm{~A}}$ agonist 8-OHDPAT dose-dependently interferes with the establishment and the expression of lithium-induced conditioned rejection reactions in rats. Psychopharmacology, 166, 120-126.

Nolan, L. J., McCaughey, S. A., Giza, B. K., Rhinehart-Doty, J. A., Smith, J. C., \& Scotт, T. R. (1997). Extinction of a conditioned taste aversion in rats: I. Behavioral effects. Physiology \& Behavior, 61, 319-323.

PARKER, L. A. (2003). Taste avoidance and taste aversion: Evidence for two different processes. Learning \& Behavior, 31, 165-172.

Rosas, J. M., \& Bouton, M. E. (1996). Spontaneous recovery after extinction of a conditioned taste aversion. Animal Learning \& Behavior, 24, 341-348. 
WAGNER, A. R., \& BRANDON, S. E. (1989). Evolution of a structured connectionist model of Pavlovian conditioning (AESOP). In S. B. Klein \& R. R. Mowrer (Eds.), Contemporary learning theories: Pavlovian conditioning and the status of traditional learning theory (pp. 149189). Hillsdale, NJ: Erlbaum.

WolgIN, D. L., \& WADE, J. V. (1990). Effect of lithium chloride-induced aversion on appetitive and consummatory behavior. Behavioral Neuroscience, 104, 438-440.

Yamamoto, J., Fresquet, N., \& SAndner, G. (2002). Conditioned taste aversion using four different means to deliver sucrose to rats. Physiology \& Behavior, 75, 387-396.

Zalaquett, C. P., \& Parker, L. A. (1989). Further evidence that CTAs produced by lithium and amphetamine are qualitatively different. Learning \& Motivation, 20, 413-427.

(Manuscript received January 7, 2005; revision accepted for publication June 7,2005 .) 